\title{
Prof. Sherrington's Work on the Nervous System.
}

By Dr. E. D. Adrian.

$\mathrm{P}$ ROF. C. S. SHERRINGTON, who was elected president of the Royal Society at the anniversary meeting on November 30 , is well known as the leading authority on the physiology of the central nervous system. The guiding principles of his researches are to be found in his book on "The Integrative Action of the Nervous System," based on the text of the Silliman lectures which he delivered in Yale University in $x 906$. This book gathers up the arguments of the most important of his papers on the physiology of the nervous system, and it is safe to say that no other book in any language has had such an immediate and profound effect on our conceptions of neurology.

The integrative function of the nervous system has long been recognised. An animal which has attained some degree of complexity is made up of different groups of cells forming the muscles, glands, supporting frame work, etc., and each $\mathrm{group}$ is specially adapted to carry out certain functions. If these different cell groups are to work harmoniously together, their activities must be coordinated with one another and with the environment of the organism, so that a change in environment will cause a response in the animal as a whole, and not merely a series of disconnected responses in the different active tissues. This integration is carried out by the nervous system, which forms a complex network of nerveNo. 2666 , vol. Io6] cells and nerve-fibres connected, on one hand with the sense-organs, and on the other with the different muscles and glands. A disturbance of equilibrium initiated in the sense-organs travels rapidly along the sensory nerves to the central mass of nervous tissue in the spinal cord and brain. Every moment an immense number of impulses are entering the central nervous system from the million or mor e sensory fibres connected to the receptive organs, and other impulses are continually passing out down the motor nerves to the muscles. Any change in the environment will modify the inflow of sensory impulses and call for some change in the activity of the animal, and the whole function of the central nervous system consists in adjusting the passage of impulses through it so that the total effect produced by the outgoing impulses to the active tissues bears an appropriate relation to the total effect of the in going sensory impuls es. The aim of the neurologist is, therefore, to discover the means by which this adjustment of the flow of impulses is carried out. There are, roughly, three main lines of research by which the problem has been approached. The first method consists in tracing the connections of the different fibres and cell groups in the nervous system, so as to map out the path by which the impulses must travel. The second attempts to find out the contribution made by different parts of the nervous system (e.g. the 
cerebellum or the cortex) to the working of the system as a whole. Both methods have yielded information of great importance, but neither of them gives much prospect of explaining the intimate nature of the processes involved in nervous co-ordination. The third, a field relatively barren until Prof. Sherrington's work, consists in analysing the simplest activities of the nervous system by a detailed study of the reflexes.

A "simple reflex"-i.e. the performance of an isolated movement as the direct consequence of sensory stimulation -is generally regarded as the unit reaction of the nervous system, the behaviour of the animal being compounded out of a series of simple reflexes. But as this compounding of reflexes is the chief work of the nervous system it is naturally a difficult matter to isolate a single reaction out of the whole behaviour of the organism; indeed, in an animal which is intact we find that the response to a given stimulus may depend not only on that stimulus, but also on the total effect of all the sensory impulses which are entering the central nervous system or have entered it previously. Prof. Sherrington overcame this difficulty by isolating a part of the central nervous system, so that relatively few sensory impulses can reach it, and the reflex response to a given stimulus can be studied under approximately constant conditions. His method takes advantage of the fact that in the higher animals the great majority of sensory impulses are those which enter the brain from the special sense-organs in the head. These organs-the eye, ear, and nose-supply information about events happening at a distance, and it is on such information that the behaviour of the higher animals is largely based. For this reason the brain has come to be the most important part of the nervous system, and is in complete control of the more primitive spinal cord which receives impulses only from sense-organs in the skin and in the interior of the body.

If the brain is cut off from the spinal cord, the latter is at first completely disorganised, but in a short time it recovers from the initial shock, and carries out simple movements of the limbs in response to stimulation of the skin or of the sensory nerve-fibres. These simple reflexes will now occur with almost mechanical regularity, because the spinal cord is isolated from the great mass of continually changing impulses which would otherwise reach it from the brain. In practice the animal is anæsthetised and the brain destroyed, usually by cutting off the entire head; as the breathing will cease, some form of artificial respiration must be employed, but with this the decapitated carcase will continue to show reflex movements for many hours. Prof. Sherrington has carried out a detailed analysis of certain of these spinal reflexes, in particular the scratching movements of the hind leg in response to irritation of the shoulder area, the withdrawal of the foot on the application of a painful stimulus, and various movements which form a part of the act of walking. He has studied also the "tonic" reflexes whereby the animal maintains a continued posture by the steady contraction of certain groups of muscles.

As a result of this method of research, he has been able to show the chief differences between conduction in the simple nerve-fibre and in the more complicated pathway through the central riervous system. He has shown how reflexes are compounded together so that two antagonistic muscles (e.g. the flexors and extensors of a limb) can never be called into play at the same moment, and how one reflex becomes fatigued and gives place to another so that the pattern of nervous conduction is continually changing and the behaviour of the animal varies even though the environment remains unaltered. The general principles of reflex action which Prof. Sherrington has formulated have had an immediate practical application to the problems of nervous disease and experimental psychology, and it is no exaggeration to say that his researches have opened up an entirely new chapter in the physiology of the central nervous system.

\section{Industrial Research Associations.}

\section{IV.-The British Research Association for the Woollen and Worsted Industries.}

\section{By Arnold Frobisher.}

THE main object of the British Research Association for the Woollen and Worsted Industries is to promote co-operation amongst wool-using firms with the view of establishing a national scheme of research into the problems presented by the woollen and worsted industries. In the formation of the association, and in the matter of providing facilities for some work that has already been done, much assistance has been given by educational bodies. particularly by Leeds University and by the Bradford Technical College.

The scope of the work of the association includes the investigation of problems arising in all branches of the woollen and worsted industries- that is to say, the growth of wool, scouring, carbonising, carding, combing, spinning, weaving, hosiery 'manufacture, dyeing, bleaching, printing, finishing, and other auxiliary or related processes. As certain classes of "woollen" goods also contain substitute fibres, the investigation of these is also necessary.

One of the first duties of the council of the association has been to make a survey of the field of research which is likely to be beneficial to the industry. In this connection members of the association can be of great assistance in the framing of a thoroughly comprehensive scheme by making suggestions relating to that part of the

$$
\text { No. } 2666 \text {, VOL. I06] }
$$

